\title{
Quan hệ hữu nghị hợp tác hiệu quả, thiết thực giữa Thành phố Hồ Chí Minh với Cộng hòa Dân chủ Nhân dân Lào - Điển hình của công tác đối ngoại tại địa phương
}

\section{Effective and practical friendly cooperation between Ho Chi Minh City and Lao People's Democratic Republic - A typical example of external relations at local level}

\author{
Trần Đình Vũ Hải $1^{*}$ \\ ${ }^{1}$ Sở Ngoại vụ Thành phố Hồ Chí Minh, Bộ Ngoại giao, Việt Nam \\ *Tác giả liên hệ, Email: haitdv@mofahcm.gov.vn
}

THÔNG TIN

DOI:10.46223/HCMCOUJS. soci.vi.16.2.1781.2021

Ngày nhận: 29/03/2021

Ngày nhận lại: 22/04/2021

Duyệt đăng: 29/04/2021

Tù khóa:

hữu nghị vĩ đại; hợp tác; hiệu quả; thiết thực

Keywords:

great friendship; cooperation; effectiveness; practicality

\section{TÓM TẮT}


huấn Đảng Nhân dân Cách mạng Lào, 2012, p. 74).

Hai nước Việt - Lào có mối quan hệ láng giềng truyền thống lâu đời, không ngừng được vun đắp qua bao thế hệ. Tình hữu nghị Việt - Lào sắt son mà thắm đẫm nghĩa tình đã trở thành tài sản vô giá của nhân dân hai nước. Từ khi thiết lập quan hệ ngoại giao (05/09/1962) và ký kết Hiệp ước hữu nghị và hợp tác (18/07/1977), quan hệ hai nước Việt - Lào đã chuyển sang giai đoạn mới: quan hệ hữu nghị vĩ đại, đoàn kết đặc biệt và hợp tác toàn diện. Từ đó đến nay, mối quan hệ Việt - Lào ngày càng được củng cố, vun đắp và không ngừng phát triển mạnh mẽ.

Một năm nữa, năm 2022, nước ta và nước bạn cùng kỷ niệm 60 năm Ngày thiết lập quan hệ ngoại giao Việt Nam - Lào (05/09/1962 - 05/09/2022) và 45 năm Ngày ký Hiệp ước hữu nghị và hợp tác Việt Nam - Lào (18/07/1977 - 18/07/2022). Nhìn lại chặng đường đã qua, chúng ta vui mừng nhận thấy quan hệ hữu nghị hợp tác đặc biệt giữa Thành phố Hồ Chí Minh với các địa phương Lào, trong đó có quan hệ kết nghĩa với Thủ đô Viêng Chăn (thiết lập từ năm 2001), tỉnh Savannakhet (từ năm 2018), Champassak (từ năm 2001), như một quan hệ hợp tác quốc tế cấp địa phương tiêu biểu của Thành phố.

Trên cơ sở từ những báo cáo quan hệ Việt Nam, Thành phố Hồ Chí Minh với Lào, đồng thời tham chiếu với các cặp quan hệ song phương khác, với sự tích lũy kinh nghiệm thực tiễn công tác của cán bộ Bộ Ngoại giao phụ trách về Lào tại Thành phố, tôi xin phép tổng hợp nội dung, số liệu công tác thường xuyên để trình bày quan hệ hữu nghị hợp tác giữa Thành phố với các Bộ, ngành địa phương Lào, như một điển hình thiết thực, hiệu quả, tốt đẹp của công tác đối ngoại tại địa phương.

\section{Thực trạng quan hệ hữu nghị hợp tác Thành phố Hồ Chí Minh - Lào}

Các chuyến thăm cấp cao lẫn nhau của lãnh đạo địa phương đã diễn ra thường xuyên, không ngừng vun xới và thắt chặt tình anh em giữa nhân dân Thành phố Hồ Chí Minh với nhân dân các địa phương Lào, thúc đẩy hợp tác trên nhiều lĩnh vực, đặc biệt là chia sẻ kinh nghiệm trong công tác xây dựng Đảng, đoàn thể, tài chính, thuế, nông nghiệp, thương mại, y tế và giáo dục với những dự án thiết thực vì lợi ích của nhân dân và sự phát triển bền vững ở mỗi địa phương. Hàng năm Thành phố Hồ Chí Minh gần 30 đoàn lãnh đạo các cấp của Lào từ Trung ương và các địa phương Lào. Việc thường xuyên được chọn là nơi tổ chức các buổi trao đổi, học tập kinh nghiệm của các đoàn cán bộ cấp cao của Lào cho thấy sự tin tưởng và quan tâm của các cấp lãnh đạo hai nước đối với Thành phố.

Cứ mỗi 05 năm một lần, nhằm thiết thực kỷ niệm Ngày thiết lập quan hệ ngoại giao và Ngày ngày ký Hiệp định hợp tác Việt Nam - Lào, Thành phố Hồ Chí Minh cùng với các địa phương phía bạn tổ chức các chuỗi hoạt động chào mừng tại mỗi địa phương nhau. Trong khuôn khổ chuyến thăm hữu nghị Lào của Đoàn đại biểu cấp cao Thành phố Hồ Chí Minh do Lãnh đạo cấp Ủy viên Trung ương Đảng trở lên dẫn đầu (Đồng chí Lê Thanh Hải, nguyên Ủy viên Bộ Chính trị, nguyên Bí thư Thành ủy năm 2007, 2012, Đồng chí Tất Thành Cang, nguyên Ủy viên Trung ương Đảng, Phó Bí thư Thường trực Thành ủy 2017), cũng như thăm Thành phố Hồ Chí Minh của Lãnh đạo cấp cao các địa phương Lào, Thành phố đã phối hợp với các địa phương Viêng Chăn, Champasak, Savannakhet, Xiêng Khoảng tổ chức Những ngày Thành phố Hồ Chí Minh, Triển lãm ảnh quan hệ đặc biệt Việt - Lào, Thành phố Hồ Chí Minh - Lào, Hội nghị xúc tiến thương mại - đầu tư, trao tặng sách vở, trang thiết bị giáo dục, trồng cây hữu nghị, các chương trình giao lưu biểu diễn nghệ thuật, ...

Nhằm thúc đẩy dòng vốn đầu tư của các doanh nghiệp Thành phố Hồ Chí Minh vào Lào, hàng năm Thành phố đều đặn tổ chức các Hội nghị, Hội chợ xúc tiến đầu tư thương mại du lịch vào Lào, như tại Viêng Chăn tháng 05/2015, Thành phố đã hỗ trợ tỉnh Xaysomboun tổ chức Hội nghị xúc tiến đầu tư vào Tỉnh Xaysomboun tại Thành phố tháng 04/2016, Hội nghị xúc tiến 
thương mại, đầu tư và du lịch vào Trung Lào (các tỉnh Savannakhet, Khammuon, Bolikhamsay vào ngày 19/07/2017), giới thiệu tiềm năng và nhu cầu kêu gọi đầu tư của các tỉnh này đến doanh nghiệp Thành phố. Bên cạnh đó, trong hai năm qua, nhiều hội nghị xúc tiến, gặp gỡ doanh nghiệp được tổ chức thông qua hình thức trực tuyến, nhiều Sở, ngành hai bên sang thăm lẫn nhau và kí kết các văn bản hợp tác như Ủy ban Mặt trận Tổ quốc Việt Nam Thành phố, Sở Du lịch, Sở Thông tin Truyền thông, Sở Văn hóa, Thể thao và Du lịch, ...

Những năm qua, Thành phố tiếp tục hỗ trợ cho các địa phương của Lào trong các dự án ở các lĩnh vực như nông nghiệp, tài chính, văn hoá du lịch, quy hoạch đô thị, bồi dưỡng nghiệp vụ cho các Sở Ban ngành. Cụ thể: với Thủ đô Viêng Chăn, Thành phố đang tích cực triển khai Chương trình hợp tác giai đoạn 2015 - 2020, đặc biệt là dự án hỗ trợ kỹ thuật chăn nuôi cải tạo đàn bò thịt; nâng cao kỹ năng quản lý tài chính cho cán bộ ngành tài chính, mở rộng hợp tác trong ngành du lịch và văn hóa. Với Champasak, Thành phố đã hoàn thành việc giúp bạn lập đồ án quy hoạch Thị trấn Paksong và xây dựng định hướng hợp tác giai đoạn 2016 - 2020. Với Xiêng Khoảng, Thư viện Tỉnh được Thành phố hỗ trợ khánh thành và đưa vào hoạt động. Ngoài ra, các sở ngành Thành phố thường xuyên hỗ trợ tập huấn về chuyên môn, nghiệp vụ cho cán bộ các địa phương Lào như Sở Tài chính, Sở Thông tin và Truyền thông, Sở Văn hóa và Thể thao, Sở Tư pháp, Sở Nông nghiệp và Phát triển Nông thôn.

Quan hệ hợp tác giữa các tổ chức chính trị xã hội của Thành phố Hồ Chí Minh và các địa phương Lào hết sức chặt chẽ và thường xuyên, thông qua việc phối hợp tổ chức các hoạt động, triển khai các chương trình hợp tác của Mặt trận, Đoàn thể, Phụ nữ, từ thiện - xã hội, giao lưu thanh thiếu niên, ... Thành Đoàn Thành phố Hồ Chí Minh hàng năm tổ chức chiến dịch Tình nguyện Mùa hè xanh, Kỳ nghỉ hồng tại các tỉnh Nam Lào với những nội dung thiết thực như khám chữa bệnh, phát thuốc cho nhân dân, tập huấn y tế, giao lưu văn hóa văn nghệ, thể dục thể thao, sửa chữa nhà dân, xây nhà tình nghĩa, làm cầu đường, ...

Giáo dục đóng vai trò quan trọng trong khuôn khổ hợp tác giữa Thành phố Hồ Chí Minh với các địa phương của Lào. Nhận thức việc nâng cao chất lượng nguồn nhân lực là yếu tố then chốt cho sự phát triển bền vững của quan hệ song phương, từ năm 2002 đến nay Thành phố đã bắt đầu cấp học bổng đào tạo đại học và sau đại học cho các địa phương Lào, đón nhận với tấm lòng chân thành và hết lòng chăm lo việc ăn học cho con em học sinh, sinh viên nước bạn Lào. Tổng cộng từ 2002 đến năm 2020, tổng số lưu học sinh Lào được Thành phố cấp học bổng hơn 600 bạn. Chỉ tiêu học bổng Thành phố cho các địa phương Lào hàng chục suất mỗi năm (Viêng Chăn 15 suất học bổng, Champasak 20 suất, Luông Phrabang 10 suất, Hủa Phăn 10 suất và Xiêng Khoảng 10 suất). Ngoài ra, Thành phố còn cấp học bổng cho các địa phương khác như Attapư, Savannaket, Sekong, Phongsaly, Udomxay, Tổng Lãnh sự quán Lào tại Thành phố Hồ Chí Minh (năm học 2017 - 2018, Thành phố cấp thêm 49 suất học bổng ngoài kế hoạch theo đề nghị của các tỉnh Hủa Phăn, Savanakhet, Tổng Lãnh sự quán Việt Nam tại Luông Phrabang và Tổng Lãnh sự quán Lào tại Thành phố Hồ Chí Minh). Hiện nay, tổng số lưu học sinh Lào đang học tại Thành phố trong 05 năm 2016 - 2020 hơn 160 bạn.

Nhằm tạo điều kiện vật chất tốt nhất cho sinh viên Lào có nơi ăn học ổn định, Thành phố đã dành hẳn một tòa nhà khang trang, ngay tại trung tâm Thành phố làm ký túc xá cho các em. Nhằm triển khai kết quả chuyến công tác Lào của Bí thư Thành ủy Nguyễn Thiện Nhân năm 2018, Sở Giáo dục và Đào tạo Thành phố chủ trì mời Đoàn cán bộ, giáo viên và học sinh hai trường Phổ thông Trung học Hữu nghị Viêng Chăn - Thành phố Hồ Chí Minh, Phổ thông Trung học Hữu nghị Việt - Lào Thủ đô Viêng Chăn (gồm 40 người) đến thăm và giao lưu tại Thành phố $\rightarrow$ bổ sung thêm.

Tình cảm anh em láng giềng cũng như tấm lòng nhân ái truyền thống của nhân dân Việt Nam được khắc họa xúc động qua những giọt nước mắt hạnh phúc của những bệnh nhân nghèo 
khiếm thị của bà con nhân dân các bộ tộc Lào anh em được thắp sáng nhờ chương trình mổ mắt miễn phí do Hội Bảo trợ Bệnh nhân nghèo thành phố Hồ Chí Minh thực hiện. Đến nay, đã có hơn 5,000 bệnh nhân nghèo khiếm thị ở các địa phương được mổ mắt và tìm lại được ánh sáng cuộc đời. Cùng với các chương trình mổ mắt miễn phí, Thành phố Hồ Chí Minh tổ chức lớp chuyển giao kỹ thuật mổ mắt và tập huấn cho các bác sĩ của bạn tại Bệnh viện mắt Thành phố.

Năm 2020 qua, do diễn biến phức tạp của tình hình dịch Covid-19 trên thế giới, nhằm tập trung vào công tác phòng, chống dịch, Thủ tướng Chính phủ đã yêu cầu tạm hoãn các đoàn đi công tác nước ngoài tại văn bản số $1774 / \mathrm{VPCP}-\mathrm{QHQT}$ ngày 08/03/2020. Tại Thành phố, ngày 10/03/2020, Lãnh đạo Thành phố cũng đã yêu cầu tất cả cán bộ, công chức, viên chức của Thành phố không được đi nước ngoài, cho đến khi có chủ trương mới. Bên cạnh đó, Thành phố tập trung tổ chức thành công Đại hội Đại biểu các cấp, hướng tới Đại hội Đại biểu Đảng bộ Thành phố Hồ Chí Minh lần thứ XI nhiệm kỳ 2020 - 2025. Căn cứ vào thực tế khách quan trên, lãnh đạo Thành phố đã có Công văn báo cáo Thủ tướng Chính phủ, Bộ Ngoại giao về việc không tổ chức các đoàn ra của Lãnh đạo Thành phố trong năm 2020, trong đó có chuyến thăm Lào, Campuchia của Chủ tịch Ủy ban Nhân dân Thành phố. Trong trường hợp dịch bệnh Covid-19 được kiểm soát, các chuyến thăm, làm việc nước ngoài được khôi phục, khả năng cao thăm Lào là đầu tiên. Điều này rất có ý nghĩa trong công tác đối ngoại của Thành phố Hồ Chí Minh và đối với quan hệ hữu nghị vĩ đại, đoàn kết đặc biệt Việt Nam - Lào.

Các cơ quan, tổ chức Thành phố đã chung tay thành lập Quỹ Phòng, chống Covid-19 và có những hoạt động thiết thực vào công việc chung này. Các Hội Hữu nghị Việt Nam - ASEAN, Hội Hữu nghị Việt Nam - Lào, cơ quan, đơn vị Thành phố Hồ Chí Minh đã hỗ trợ các địa phương Lào (Viêng Chăn, Champasak ...). Xuất phát với tình cảm chia sẻ, quan tâm, Lãnh đạo Thành phố đã gửi điện thăm hỏi các địa phương quốc tế có quan hệ hữu nghị hợp tác trên thế giới, trong đó có các địa phương Lào (Viêng Chăn, Savannakhet, Champasak) ... và xem xét tặng máy trợ thở, máy đo thân nhiệt, khẩu trang, thuốc men cho một số tỉnh, thành kết nghĩa của Lào, Campuchia (như Viêng Chăn, Luông Phrabang). Trong bối cảnh Thành phố đang khôi phục lại các hoạt động kinh tế - xã hội theo trạng thái "bình thường mới," Thành phố chủ động thúc đẩy việc duy trì quan hệ hợp tác địa phương thông qua nền tảng số, internet giữa Thành phố Hồ Chí Minh và các địa phương nước ngoài. Sở Ngoại vụ Thành phố Hồ Chí Minh đã chủ trì phối hợp tổ chức thành công nhiều hội nghị với đối tác nước ngoài bằng hình thức trực tuyến và xem xét tính khả thi việc triển khai ngoại giao số với các địa phương Lào.

Trong năm 2020, quan hệ hữu nghị hợp tác quốc tế của Thành phố tiếp tục mở rộng với mười một bản Thỏa thuận quốc tế được ký kết giữa Chính quyền và các Sở ngành Thành phố với các đối tác nước ngoài. Năm 2020, các cơ quan địa phương của Thành phố và Thủ đô Viêng Chăn, Tỉnh Champasak, Savannakhet do Sở Ngoại vụ mỗi bên làm đầu mối đã tiến hành trao đổi, rà soát đánh giá kết quả hợp tác trong giai đoạn 2016 - 2020 và chuẩn bị nội dung để kí kết Biên bản định hướng hợp tác song phương giai đoạn 2021 - 2025. Dù chịu tác động của dịch bệnh, nhưng trong năm qua Thành phố vẫn tiếp nhận hàng chục lưu học sinh Lào sang học như cam kết, thực hiện đúng các quy trình cách ly, phòng, chống dịch. Về các dự án văn hóa cụ thể, Sở Văn hóa và Thể thao chủ trì và phối hợp Sở Ngoại vụ triển khai Dự án tu bổ Khu di tích lịch sử Bác Hồ tại tỉnh Savanakhet.

\section{Quan hệ hữu nghị hợp tác Thành phố Hồ Chí Minh - Lào hướng tới tương lai}

Việc có được những thành quả hợp tác hiệu quả, thiết thực, đầy ý nghĩa trên là do các cấp lãnh đạo Đảng, Hội đồng Nhân dân, Chính quyền, Mặt trận Tổ quốc Việt Nam Thành phố Hồ Chí Minh đến các sở, ban ngành đã không ngừng quan tâm, tạo điều kiện thuận lợi nhất để thúc đẩy, làm cho mối quan hệ hợp tác ngày càng được nâng cao và có hiệu quả, tương xứng với quan hệ chính trị hết sức tốt đẹp giữa hai dân tộc Việt Nam và Lào. Trong bối cảnh hội nhập và phát 
triển hiện nay, việc củng cố và thúc đẩy hơn nữa quan hệ hữu nghị vĩ đại, đàon kết đặc biệt, hợp tác toàn diện Việt Nam - Lào nói chung, giữa Thành phố Hồ Chí Minh và các địa phương kết nghĩa Lào nói riêng, có ý nghĩa hết sức quan trọng, phù hợp với lợi ích căn bản và nguyện vọng thiết tha của nhân dân hai nước.

Những kết quả thiết thực, hiệu quả và ý nghĩa có được trong thời gian qua giúp chúng ta vững tin vào hợp tác với nước bạn Lào trong những năm tiếp theo. Phương hướng chung trong thời gian tới, phía Thành phố cùng Bộ, ngành địa phương cả nước ý thức sâu sắc củng cố quan hệ hữu nghị vĩ đại, đoàn kết đặc biệt, lòng tin chính trị và đan xen lợi ích thông qua hợp tác trên tất cả các lĩnh vực; chú trọng nâng cao hiệu quả hợp tác kinh tế theo hướng bình đẳng, cùng có lợi và bền vững, thúc đẩy giải quyết dứt điểm các dự án của doanh nghiệp Thành phố còn tồn đọng; đẩy mạnh hỗ trợ cán bộ các cấp của bạn, đặc biệt là giao lưu thế hệ trẻ.

Trên cơ sở đó, Thành phố xem xét, góp phần triển khai hiệu quả Đề án phát triển quan hệ Việt Nam - Lào giai đoạn 2021 - 2025 và những năm tiếp theo; nâng cao chất lượng, hiệu quả trao đổi đoàn các cấp, thực hiện đầy đủ các thỏa thuận, bản ghi nhớ hợp tác; tăng cường hợp tác kinh tế, hỗ trợ các doanh nghiệp Thành phố xúc tiến thương mại, đầu tư sang Lào, tiếp tục thúc đẩy thực hiện các dự án cụ thể; đóng góp vào nỗ lực chung hỗ trợ đào tạo nguồn nhân lực, nâng cao chất lượng đào tạo cán bộ địa phương nhằm đáp ứng nhu cầu phát triển của bạn, gắn bó với Việt Nam qua các chương trình thiết thực như xây dựng Ký túc xá Lào, Chương trình lưu học sinh Lào và người dân Thành phố, Kỳ nghỉ hồng, ...

\section{Quan hệ ngoại giao Việt Nam - Lào từ góc nhìn của một nhà ngoại giao phụ trách}

Hướng đến kỷ niệm 60 năm Ngày thiết lập quan hệ ngoại giao và 45 năm Ngày ký Hiệp ước hữu nghị hợp tác của hai đất nước, hai dân tộc Việt Nam - Lào sắp tới, là cán bộ ngoại giao Phòng Chính trị Kinh tế Đối ngoại, Sở Ngoại vụ Thành phố Hồ Chí Minh, Bộ Ngoại giao, phụ trách công tác Lào trong suốt 17 năm qua, nhìn lại chặng đường công tác đã qua của mình, tôi vinh dự và tự hào được gần 50 lần tháp tùng Lãnh đạo Thành phố, Lãnh đạo Sở ngành thăm, công tác tại Lào và vinh dự được đặt chân đến mọi miền đất nước Lào (13/18 tỉnh, thành). Tôi gắn bó, lưu luyến và giữ mãi trong lòng hình ảnh đất nước hoa Champa tươi đẹp, hiền hòa cùng những tình cảm tốt đẹp của Lãnh đạo, đồng nghiệp và nhân dân các bộ tộc Lào anh em giành cho mình. Để hoàn thành tốt các nhiệm vụ của một nhà ngoại giao, tôi cần không ngừng ra sức học hỏi, trau dồi chuyên môn, chăm chỉ công tác, chia sẻ kinh nghiệm với đồng nghiệp, chân thành mong góp phần nho nhỏ của mình trong việc kế tục, gìn giữ và phát triển mối quan hệ được xây dựng bằng rất nhiều công sức và xương máu của nhân dân hai nước và thật tâm trông nguyện tình hữu nghị đặc biệt giữa Đảng, Nhà nước và nhân dân hai nước Việt - Lào, trong đó có Thành phố Hồ Chí Minh với các địa phương nước bạn, lại càng thắm thiết, bền chặt, quyến luyến hơn. Trường Sơn hùng vĩ, Mê Kông sâu dài, điệu nhảy Lămvông của người dân Lào hiền lành say đắm. Giọt nước, hạt đất xứ sở Triệu Voi luôn đong đầy niềm cảm xúc, luôn dày ngọt, sâu lắng nghĩa tình, ...

Một lần trong chuyến công tác, phụ trách chương trình nội dung cho Đoàn đại biểu cấp cao Thành phố Hồ Chí Minh thăm, làm việc tại Thủ đô Viêng Chăn, các tỉnh Hủa Phăn, Xiêng Khoảng, Luông Phrabang, Bolikhamsay, Khăm Muộn, Savannakhet, Champasak vào tháng 12/2016, được trải nghiệm chân thật về tình cảm quyến luyến, nghĩa tình của Lãnh đạo và người dân nước bạn, được thăm và hiểu thêm các di tích lịch sử, cách mạng, văn hóa dân tộc, tôi xúc động và ghi lại tình cảm của mình qua những câu thơ lục bát. Câu thơ tuy không hay, nhưng ý và tình cảm là chân thành.

Hủa Phăn xanh núi, mù mây,

Núi che bộ đội, mù vây quân thù. 
Viêng Xây anh dũng, oai hùng,

Sầm Nưa trang sử lẫy lừng chiến công.

Phôn Sa Vẳn, mây bềnh bồng,

Cánh Đồng Chum đá, chung lòng gió mưa.

Cố đô thăm lại đất xưa,

Trời xanh, mây trắng, mái chùa cong cong,

Phu Sỉ núi ngắm ra sông,

Hoàng cung lộng lẫy bên dòng Nậm Khan.

Viêng Chăn cô gái mơ màng,

Thủ đô xinh đẹp, dịu dàng, ấp e.

Paksan rầm rập đoàn xe,

Thà Khẹt đượm nắng vàng che quân hành.

Sa Van Na Khệt phố xuân,

Bồi hồi, xúc động, bao lần nhớ mong.

Pakse chung thủy, sắt son,

Xương hòa, máu quyện, vun trồng bền lâu.

Việt - Lào nghĩa nặng, tình sâu,

Sáu mươi năm ấy xiết bao vui buồn.

Trường Sơn nắng đổ, mưa tuôn,

Uống cùng dòng nước, chung nguồn Mê Kông.

Cao nghĩa núi, dài tình sông,

Vẫn nguyên thề hẹn, đắp dày ân kia.

Muối rau cọng hạt sẻ chia,

Dẫu bao gian khó, chẳng lìa được nhau.

Ngày nay cho đến mai sau,

Thủy chung, son sắt, bền lâu muôn đời. 


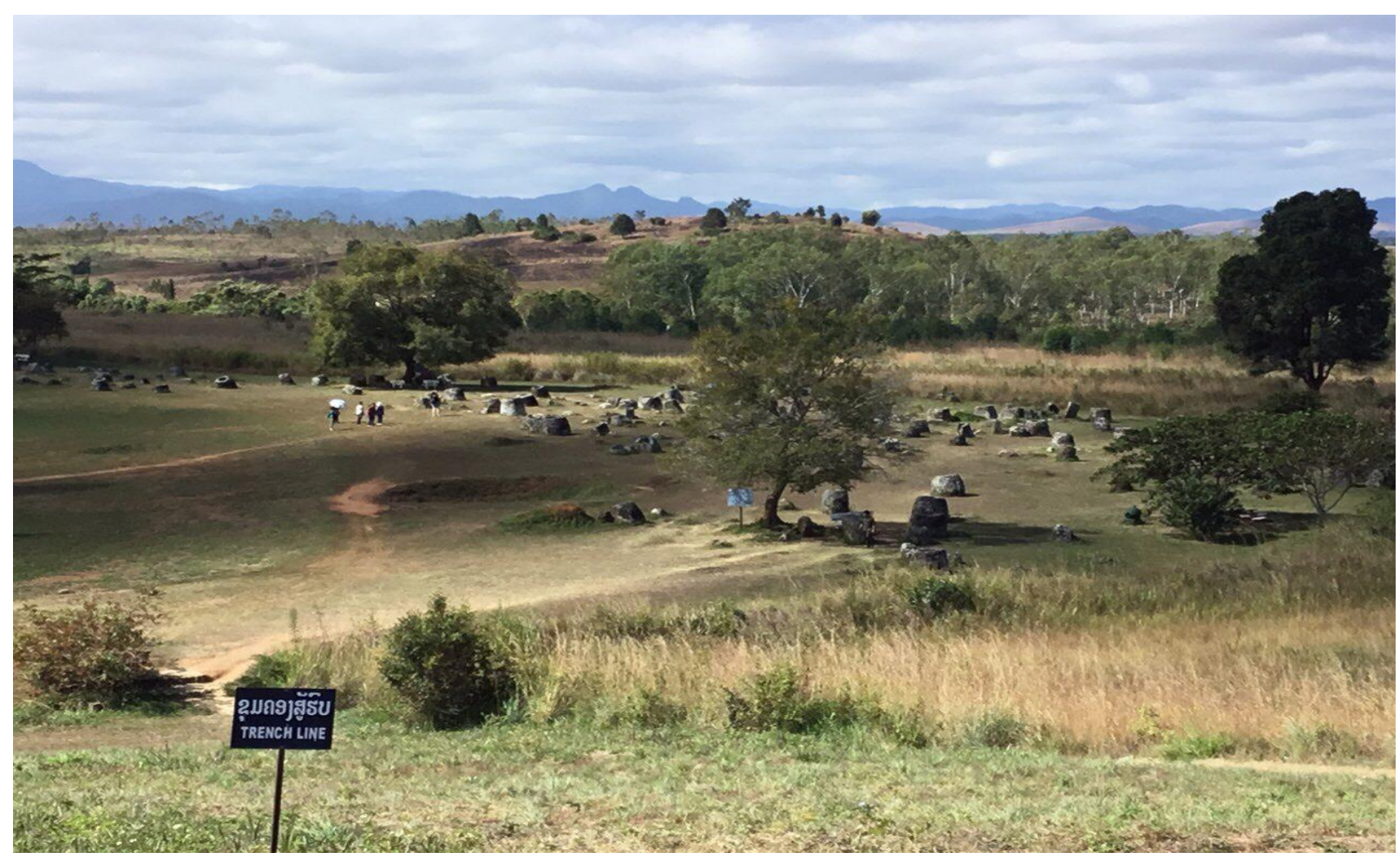

Hình 1. Cánh đồng Chum nổi tiếng tại tỉnh Xiêng Khoảng

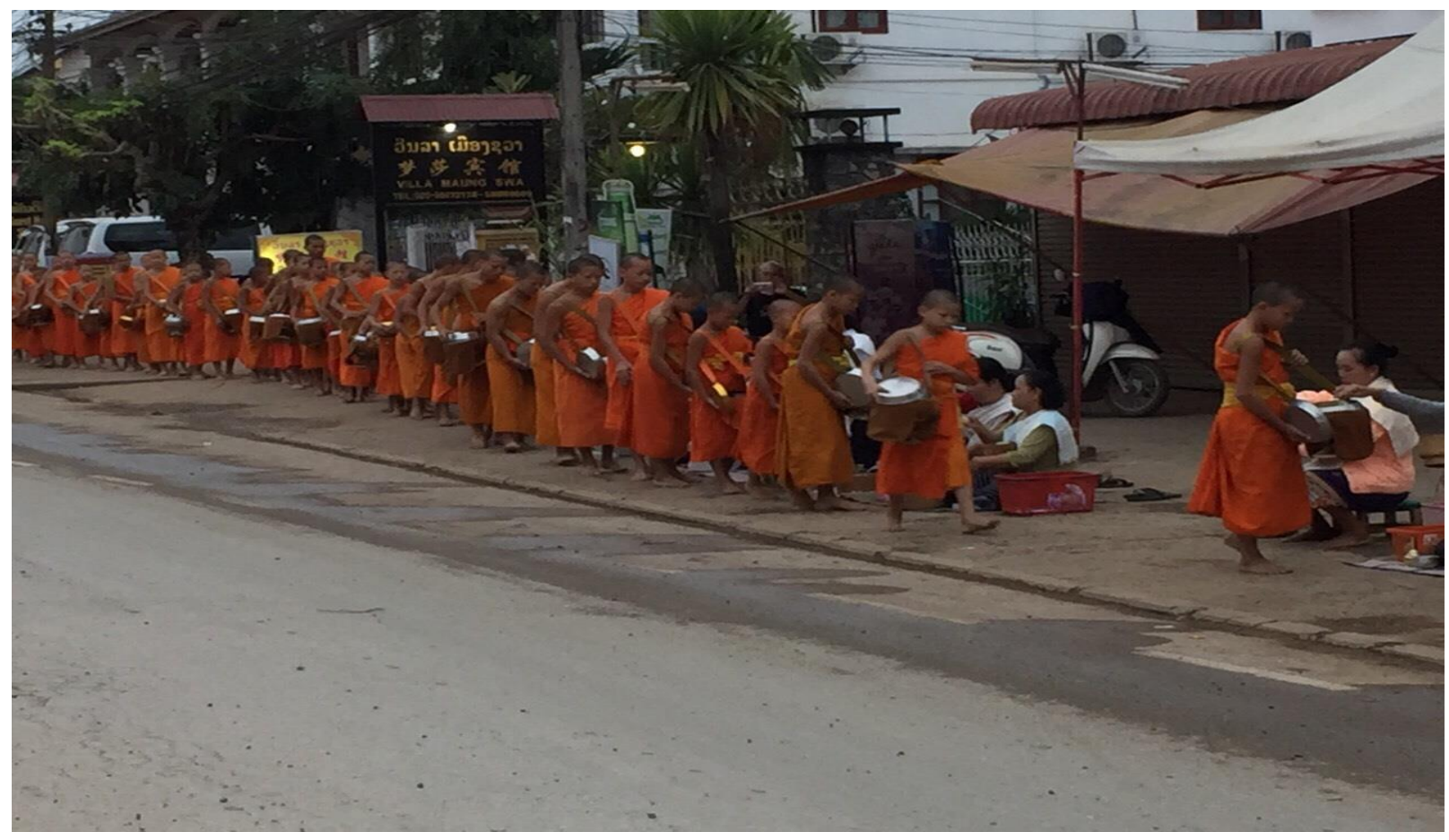

Hình 2. Đường phố cố đô Luông Phrabang

\section{Tài liệu tham khảo}

Ban Tuyên giáo Trung ương Đảng Cộng sản Việt Nam \& Ban Tuyên huấn Đảng Nhân dân Cách mạng Lào. (2012). Lịch sủ quan hệ đặc biệt Việt Nam - Lào Lào - Việt Nam 1930 - 2007 [History of Special Relations Vietnam - Laos Laos - Vietnam 1930 - 2007]. Hanoi, Vietnam: NXB Chính trị Quốc gia. 
Ban Tuyên giáo Trung ương Đảng. (2018). Tài liệu học tập các văn kiện Hội nghị lần thứ tám Ban Chấp hành Trung uoong Đảng khóa XII [Learning materials for the eighth Conference of the 12th Party Central Committee]. Hanoi, Vietnam: NXB Chính trị Quốc gia.

Báo Điện tử Đảng Cộng sản Việt Nam. (2006). Văn kiện Đại hội đại biểu toàn quốc lần thứ X của Đảng Cộng sản Việt Nam [Document of the Tenth National Congress of the Communist Party of Vietnam]. Retrieved January 20, 2021, from http://www.chinhphu.vn/portal/page/portal/chinhphu/NuocCHXHCNVietNam/ThongTinT ongHop/noidungvankiendaihoidang? categoryId=10000715\&articleId=10038386

Bộ Ngoại giao. (2002). Ngoại giao Việt Nam 1945 - 2000 [Vietnam Diplomacy 1945 - 2000]. Hanoi, Vietnam: NXB Chính trị Quốc gia.

Bộ Ngoại giao. (2011). Chính sách đối ngoại Việt Nam [Foreign policy of Vietnam]. Retrieved January 10, 2021, from http://www.mofa.gov.vn/ vi/cs_doingoai/ns110901104725/view

Bộ Ngoại giao. (2016). Đại hội XII và nhũng điểm mới về đương lối đối ngoại [XII Congress and new points on foreign policy]. Retrieved January 12, 2021, from http:// www.mofa.gov.vn/vi/nr140319210702/ns160904093015/view

Đảng bộ Đảng Cộng sản Việt Nam Thành phố Hồ Chí Minh. (2015). Văn kiện Đại họi đại biểu là̀n thứ X của Đảng bộ Đảng Cộng sản Việt Nam Thành phố Hồ Chí Minh [Document of the Tenth Congress of Representatives of the Communist Party of Vietnam in Ho Chi Minh City]. Retrieved January 18, 2021, from https://www.hcmcpv.org.vn/van-ban-vankien/van-kien-dai-hoi-dai-bieu-dang-bo-tphcm-lan-thu-X-1462530928

Le, C. D. (2017). 55 năm quan hệ ngoại giao Việt Nam - Lào: Nhìn lại và hướng tới [55 years of diplomatic relations between Vietnam and Laos: Looking back and looking forward]. Hanoi, Vietnam: NXB Thông tin và Truyền thông.

Nguyen, L. P. (2017). Việt Nam - Lào: Sụ gắn bó xuyên thời gian: Nhũng nét tương đồng về chính trị, lịch sủ, văn hóa tù cổ đại đến hiện đại [Vietnam - Laos: Attachment through time: Political, historical and cultural similarities from ancient to modern]. Hanoi, Vietnam: NXB Thông tin và Truyền thông.

Pham, M. B. (2012). Cục diện thế giới đến 2020 [World bureau to 2020]. Hanoi, Vietnam: NXB Chính trị Quốc gia.

Pham, M. B. (2021). Đường lối đối ngoại Đại hội XI và nhũng phát triển quan trọng trong tư duy đối ngoại của Đảng ta [Foreign policy of the XI Congress and important developments in our Party's external thinking]. Retrieved January 15, 2021, from http://www.mofa.gov.vn/vi/cs_doingoai/nr070523093001/ns110520170239/view

Pham, T. T. T. (2020). Thực trạng và giải pháp nâng cao quan hệ hũu nghị hợp tác Thành phố Hồ Chí Minh [Current situation and solutions to improve the friendship and cooperation in Ho Chi Minh City]. Ho Chi Minh, Vietnam: Trung tâm thông tin và Thống kê Khoa học và Công nghệ (CESTI).

Thanh Mai (2018). Công tác đối ngoại Thành phố Hồ Chí Minh nâng cao chất lượng hội nhập quốc tế [External affairs in Ho Chi Minh City improve the quality of international integration]. Retrieved January 25, 2021, from http://ww.hochiminhcity.gov.vn/thongtinthanhpho/tintuc/Lists/Posts/Post.aspx?CategoryId $=3 \&$ ItemID=59396\&PublishedDate $=2018-02-03$ T10:50:00Z 
Tran, T. N. (2015). Hoạt động ngoại giao của Thành phố Hồ Chí Minh (1975 - 2015) [Diplomatic activities of Ho Chi Minh City (1975 - 2015)]. Ho Chi Minh, Vietnam: NXB Văn hóa - Văn nghệ.

VHTTĐN. (2019). Chức năng, nhiệm vu Sở Ngoại vụ Thành phố Hồ Chí Minh. Trích Quyết định số 3663/QĐ-BNG ngày 19/12/2018 của Phó thủ tuớng, Bộ truởng Bộ Ngoại giao Phạm Binh Minh [Functions and duties Ho Chi Minh City Department of Foreign Affairs. Excerpt from Decision No. 3663 /QD-BNG dated December 19, 2018 of Deputy Prime Minister and Minister of Foreign Affairs Pham Binh Minh]. Retrieved January 16, 2021, from http://www.mofahcm.gov.vn/vi/gioithieu_snv/nr041216100909

Văn phòng Chính phủ. (2020). Công văn số 1774/VPCP-QHQT của Văn phòng Chính phủ: V/v tạm hoãn đi công tác nước ngoài ngày 08/03/2020 [Official Letter No. 1774/VPCP-QHQT of the Office of the Government: Regarding temporary postponement of overseas business trip on March 8, 2020]. Retrieved January 16, 2021, from http://vanban.chinhphu.vn/portal/page/portal/chinhphu/hethongvanban?class_id=2\&_page $=1 \&$ mode=detail \&document_id=199358 